\title{
A Brazilian Case of Tongue Cysticercosis
}

\author{
Faber Neves Santos ${ }^{1}$, Fabine Neves Santos Soares ${ }^{2}$, Cláudia Leal Macedo ${ }^{3}$, Renata Oliveira de Souza ${ }^{4}$, \\ Aline Rode Santos ${ }^{4}$, Clarissa Araújo Silva Gurgel ${ }^{4}$, Fred Luciano Neves Santos ${ }^{5^{*}}$ \\ ${ }^{1}$ Private Dental Centre, Vitória da Conquista, Brazil; ${ }^{2}$ Faculty of Nursing, Northeastern Independent College-AINOR, Vitória da \\ Conquista, Brazil; ${ }^{3}$ Private Service of Pathology and Cytopathology, Vitória da Conquista, Brazil; ${ }^{4}$ Faculty of Odontology, Federal \\ University of Bahia (UFBA), Salvador, Brazil; ${ }^{5}$ Aggeu Magalhães Research Center (CPqAM) Oswaldo Cruz Foundation (FIOC \\ RUZ), Recife, Brazil. \\ Email: *fred.santos@cpqam.fiocruz.br
}

Received September $2^{\text {nd }}, 2012$; revised October $3^{\text {rd }}$, 2012; accepted November $6^{\text {th }}, 2012$

\begin{abstract}
Human cysticercosis is a neglected tropical parasitic disease due to the tapeworm Taenia solium, common in endemic developing countries. Cysticerci are most commonly found within the central nervous system, but they may also localize in a variety of tissues, including the tongue. Here, we described a case of a 21-year-old woman with a painless, firm, smooth, mucosa-colored nodule located in the lateral region of the tongue was seen by a dentist. An excisional biopsy was performed, and the surgical specimen was examined histomorphologically. The analysis revealed the presence of a cystic lesion containing a serrated larva (Cysticercus cellulosae) as well as a cystic capsule with predominantly mononuclear inflammation. The morphological findings were consistent with the diagnosis of cysticercosis of the tongue. The patient was followed for 22 months and showed no signs of recurrence.
\end{abstract}

Keywords: Human Cysticercosis; Oral Infection; Histopathological Diagnosis

\section{Introduction}

Infection with Taenia solium, which causes intestinal taeniasis and tissue cysticercosis, comprises two different life cycle stages and clinical entities in the human host. Normally, the adult tapeworm completes the larval phase of its life cycle in pigs and is then transmitted to humans via the ingestion of undercooked contaminated pork; once inside the human host, the parasite develops into a tapeworm in the intestine [1]. The worms shed gravid segments laden with eggs into the stool, from which pigs can then be reinfected. By itself, intestinal taeniasis causes low morbidity, but it is the sole source for the more pathogenic tissue infection known as cysticercosis. Cysticercosis is a parasitic infection caused by the larval stage (Cysticercus cellulosae) of the tapeworm T. solium that can affect humans and animals, with more than 50 million individuals estimated to be infected worldwide. Cysticercosis is the major cause of seizure disorders worldwide and also causes economic losses due to infected pork [2].

The accidental ingestion of eggs by humans via fecal contamination of the fingers, food or water or through the reflux of proglottids from the intestine leads to the presence of eggs in the stomach, where the resultant em-

${ }^{*}$ Corresponding author. bryos penetrate the mucosa and are dispersed by the blood or lymphatics, leading to cysticercosis. In humans, cysticerci are most commonly found within the central nervous system, where they produce a pleomorphic clinical disorder known as neurocysticercosis [3], but they may also primarily localize in a variety of tissues, including the heart [4], muscle [5], skin [6], and eyes [7]. Although common in swine, oral cysticercosis is rare in humans, and, to date, few cases of tongue cysticercosis have been reported. In this report, we describe a case of tongue cysticercosis in a healthy woman who reported no contact with pigs.

\section{Case Report}

A 21-year-old woman from Poções County (Bahia, Brazil) reported to a private dental center with the chief complaint of a painless nodule on the right side of her tongue that had been present for the past two years. The nodule had increased in size to approximately $3.5 \mathrm{~cm}$ in maximum diameter, and clinical examination showed a firm nodule that was covered with normal mucosa (Figure 1(A)). No cervical or submandibular lymphadenopathy was observed. A complete blood count, liver function tests and renal function tests were all normal.

A preliminary diagnosis of lipoma was made, and an excisional biopsy was performed, with a well-delimited 
nodule with free surgical margins detected during surgery (Figure 1(B)). The biopsy was fixed in 10\% formalin and sent for anatomopathological examination (Figure $\mathbf{1 ( C )}$ ). The surgical excision of the nodule relieved the lingual discomfort.

An analysis of hematoxylin/eosin-stained histological sections revealed the presence of a cystic lesion containing a serrated larva (C. cellulosae) with a cuticle and well-defined areolar and cellular layers (Figure 2(A)) as well as a cystic capsule exhibiting predominantly mononuclear inflammation (Figure 2(B)). The final diagnosis was cysticercosis of the tongue.

The patient was referred for clinical evaluation. The coproparasitological exam was negative for eggs and proglottids of $T$. solium and other pathogens. A chest $\mathrm{X}$-ray and computed tomography showed no calcified cystic areas. The patient was followed for 22 months and showed no signs of recurrence.

\section{Conclusions}

Parasitic infections are endemic and represent a major public health problem in developing countries. In particular, human infections with $T$. solium occur worldwide, mainly in rural communities in developing countries in Central and South America, most parts of Asia (including the Indian subcontinent and China), Eastern Europe, and most of Africa, especially in those areas with poor sanitation where humans and animals live in close contact and in those regions where inspection of meat is not strictly enforced. Imported cases mostly occur in developed areas due to immigration from and tourism to endemic regions [8]. Brazil has one of the highest prevalences of $T$. solium infection [2].
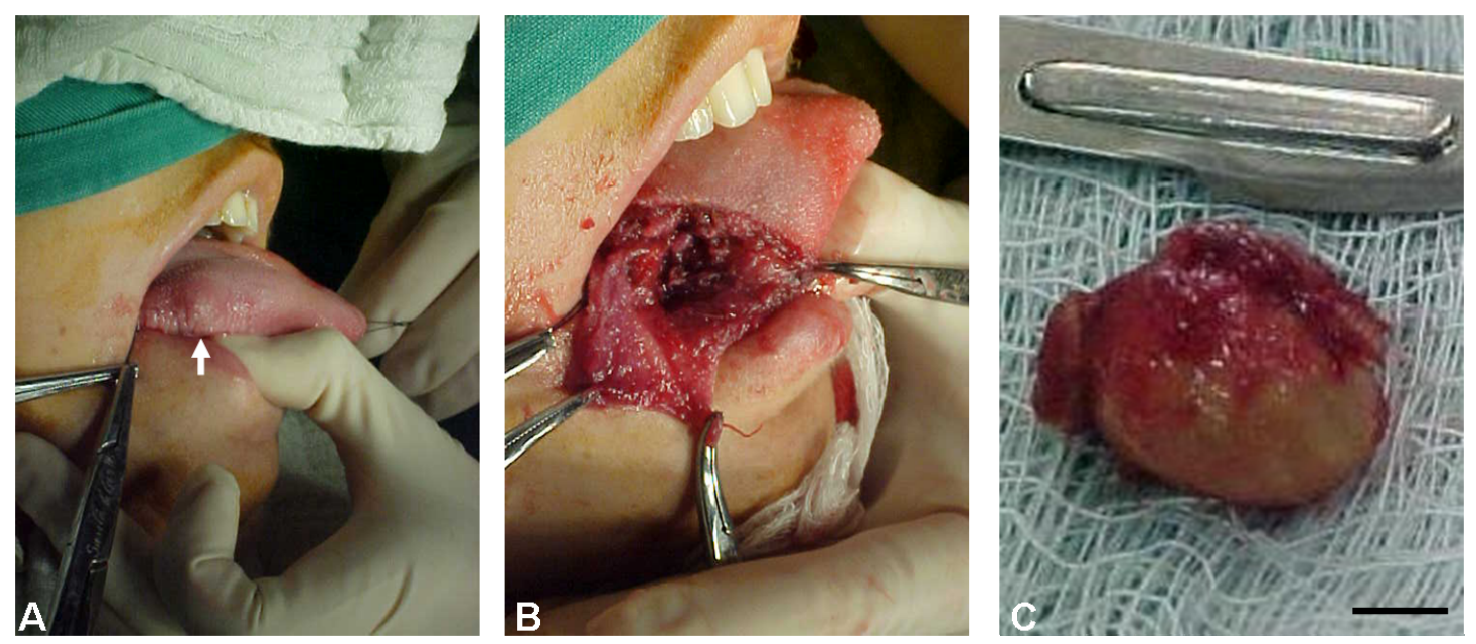

Figure 1. Cysticercosis on the right side of the tongue of a 21-year-old woman from Poções County, Bahia State (Brazil) that was initially diagnosed as a lipoma. (A) Nodular, firm swelling; (B) Intraoperative view showing the location of cyst removal; (C) Macroscopic view of the encapsulated surgical specimen. Bar $=1 \mathrm{~cm}$.
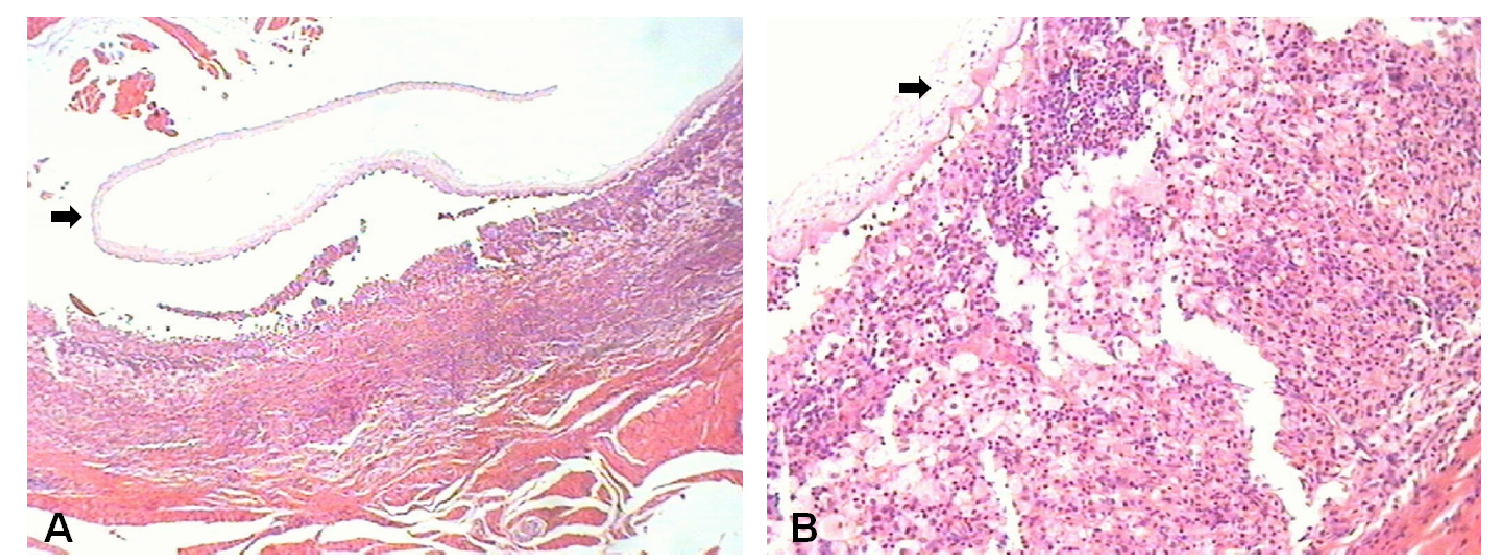

Figure 2. Histological section of the cysticercosis surgically removed from a 21-year-old woman from Poções County, Bahia State (Brazil). (A) Presence of a cystic lesion containing a serrated Cysticercus cellulosae larva with a cuticle and well-defined areolar and cellular layers (arrow); (B) Histopathological view showing a predominantly mononuclear inflammatory process encircling the cystic capsule (arrow). 
Humans are the definitive host of the adult form of the $T$. solium helminth, and pigs are the intermediate host of the larval stage. However, humans can become an accidental intermediate host of $T$. solium when viable eggs of the parasite are ingested. The eggs emerge in the intestine and are transported through the bloodstream to their destination, which is generally the heart [4], muscles [5], subcutaneous tissues [6], or eye [7]; however, eggs mainly cause disease when deposited in the central nervous system [3] where larvae develop and transform into the cysticercus form 60 to 70 days after ingestion. Cases of cysticercosis involving oral tissues are rare but may affect the tongue, lower lip and oral mucosa, in this order of prevalence $[9,10]$. The parasite can survive for up to 6 years, and during this period, it provokes an inflammatory reaction in adjacent tissues that ranges from moderate to severe [11].

It is important to stress that the risk of infection is present only when pigs are raised in a rural household environment in the absence of good hygiene, not in industrial herds or in large agricultural areas that are subject to strict sanitary control. In addition, the immigration of people from endemic to non-endemic regions has resulted in an increase in the number of cases in some industrialized countries where this condition was considered to be almost eradicated. The patient described here lives in a small rural town located in the southwest region of Bahia State (Brazil). However, she reported no contact with pigs.

Few cases of cysticercosis involving oral tissues have been reported in the literature. Similar to the present case, the tongue appears to be the most frequently affected site [9,12], and cysticercosis of the tongue should always be included in the differential diagnosis for patients who live in endemic areas and present nodular formations in the mouth. Despite the small number of cases described, the clinical manifestations of oral cysticercosis are consistent with the symptoms observed in the present case, i.e., a firm, slow-growing nodule with well-defined margins covered with normal-color mucosa that is a symptomatic. With respect to age and gender, patients in their second decade of life seem to be more affected [13], and there are no consistent data indicating a gender bias [14].

The differential diagnosis for oral cysticercosis includes salivary gland tumors and mucoceles, in addition to neurofibroma, vascular tumors, fibroma, lipoma, leiomyoma and schwannoma $[9,10]$. When cysticercosis is diagnosed in oral tissues, serological and coprological tests and imaging exams are essential for the detection of systemic disease [15]. In the present case, the coprological examination, chest $\mathrm{X}$-ray and cranial tomography were negative. Serological tests were not requested because the patient lived in an area characterized by a high incidence of parasitic diseases, and these tests have no diagnostic value in populations frequently exposed to contamination [16].

Fine-needle cytology may aid diagnosis when the larval tegument is aspirated. In the study conducted by Mazhari et al. (2001), 153 patients with cysticercosis were diagnosed using only this technique [13]. However, histopathological examination is essential for the definitive diagnosis of this parasitic disease [14]. Histological analyses reveal findings such as those that were observed in the present case, including a cystic cavity containing C. cellulosae and fibrous connective tissue permeated by a predominantly mononuclear inflammatory infiltrate.

Treatment of cysticercosis might be unnecessary in asymptomatic patients [12]. However, drugs such as praziquantel and albendazole are potent anti-helminthic agents that are used to treat the disease, especially when surgical treatment is not possible, such as for neurocysticercosis. Surgical treatment is indicated for cysts located in accessible areas, as in the case described here. A search for other nodules is recommended to exclude a more severe case, such as neurocysticercosis. Following excision of the nodule, the patient was monitored periodically for 22 months to detect recurrence of the disease, but no signs of recurrence were detected.

\section{REFERENCES}

[1] S. Lustigman, R. K. Prichard, A. Gazzinelli, W. N. Grant, B. A. Boatin, J. S. McCarthy and M. G. Basáñez, "A Research Agenda for Helminth Diseases of Humans: The Problem of Helminthiases," PLoS Neglected Tropical Diseases, Vol. 6, No. 4, 2012, p. e1582. doi:10.1371/journal.pntd.0001582

[2] World Health Organization Expert Committee, Report of the WHO Expert Consultation on Foodborne Trematode Infections and Taeniasis/Cysticercosis, Vientiane, Lao People's Democratic Republic, 12-16 October 2009. http://www.who.int/neglected_diseases/preventive_chem otherapy/WHO_HTM_NTD_PCT_2011.3.pdf

[3] A. C. White, "Why Are There Seizures in Neurocysticercosis: Is It in the Genes," Journal of Infectious Diseases, Vol. 202, No. 8, 2010, pp. 1152-1153. doi:10.1086/656396

[4] P. J. Shogan, J. F. Yasmer and M. Monson, "Cardiac Cysticercosis,” American Journal of Roentgenology, Vol. 192, No. 5, 2009, pp. 212-213. doi:10.2214/AJR.08.2000

[5] H. Yamasaki, T. Nagase, Y. Kiyoshige, M. Suzuki, K. Nakaya, Y. Itoh, Y. Saco, M. Nakao and A. Ito, “A Case of Intramuscular Cysticercosis Diagnosed Definitively by Mitochondrial DNA Analysis of Extremely Calcified Cysts," Parasitology International, Vol. 55, No. 2, 2006, pp. 127 130. doi:10.1016/j.parint.2005.11.057

[6] M. Lakhey, S. Hirachand, J. Akhter and B. Thapa, "Cysticerci in Palpable Nodules Diagnosed on Fine Needle Aspiration Cytology,” Journal of Nepal Medical Association, Vol. 48, No. 176, 2009, pp. 314-317. 
[7] K. Swastika, C. I. Dewiyani, T. Yanagida, Y. Sako, M. Sudarmaja, P. Sutisna, T. Wandra, N. S. Dharmawan, K. Nakaya, M. Okamoto and A. Ito, "An Ocular Cysticercosis in Bali, Indonesia Caused by Taenia solium Asian Genotype,” Parasitology International, Vol. 61, No. 2, 2012, pp. 378-380. doi:10.1016/j.parint.2011.11.004

[8] F. J. Sorvillo, L. Portigal, C. De Giorgio, L. Smith, S. H. Waterman, G. W. Berlin and L. R. Ash, "Cysticercosis-Related Deaths, California," Emerging Infectious Diseases, Vol. 10, No. 3, 2004, pp. 465-469. doi:10.3201/eid1003.020749

[9] F. M. Elias, M. T. Martins, R. Foronda, W. A. Jorge and N. S. de Araújo, "Oral Cysticercosis: Case Report and Review of the Literature," Revista do Instituto de Medicina Tropical de São Paulo, Vol. 47, No. 2, 2005, pp. 95-98. doi:10.1590/S0036-46652005000200007

[10] D. Mahajan, N. Khurana and N. Setia, “Coexistence of Salivary Gland Cysticercosis with Squamous Cell Carcinoma of the Mandible,” Oral Surgery, Oral Medicine, Oral Pathology, Oral Radiology, and Endodontology, Vol. 103, No. 3, 2007, pp. 47-50. doi:10.1016/j.tripleo.2006.10.001

[11] L. I. Terrazas, "The Complex Role of Pro- and Anti-Inflammatory Cytokines in Cysticercosis: Immunological Lessons from Experimental and Natural Hosts," Current Topics in Medicinal Chemistry, Vol. 8, No. 5, 2008, pp. 383-

\section{2. doi:10.2174/156802608783790848}

[12] D. J. Webb, J. Seidel and R. W. Correll, "Multiple Nodules on the Tongue of a Patient with Seizures," Journal of American Dental Association, Vol. 112, No. 5, 1986, pp. 701-702.

[13] N. J. Mazhari, N. Kumar and S. Jain, "Cysticercosis of the Oral Mucosa: Aspiration Cytologic Diagnosis,” Journal of Oral Pathology and Medicine, Vol. 30, No. 3, 2001, pp. 187-189.

[14] J. Lustmann and M. Copelyn, "Oral Cysticercosis. Review of the Literature and Report of 2 Cases," International Journal of Oral Surgery, Vol. 10, No. 5, 1981, pp. 371-375. doi:10.1016/S0300-9785(81)80038-5

[15] B. J. Mwang’onde, G. Nkwengulila and M. Chacha, “The Serological Survey for Human Cysticercosis Prevalence in Mbulu Disctrict, Tanzania,” Advances in Infectious Diseases, Vol. 2, No. 3, 2012, pp. 62-66. doi:10.4236/aid.2012.23009

[16] H. H. Garcia, L. J. Harrison, R. M. Parkhouse, T. Montenegro, S. M. Martinez, V. C. Tsang and R. H. Gilman, “A Specific Antigen-Detection ELISA for the Diagnosis of Human Neurocysticercosis. The Cysticercosis Working Group in Peru," Transactions of the Royal Society of Tropical Medicine and Hygiene, Vol. 92, No. 4, 1998, pp. 411-414. doi:10.1016/S0035-9203(98)91069-0 